\title{
Arbuscular Mycorrhizal Symbiosis for Sustainable Cultivation of Chinese Medicinal Plants: A Promising Research Direction
}

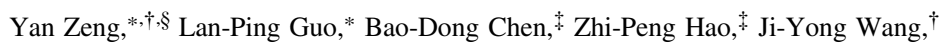 \\ Lu-Qi Huang,",\& Guang Yang, ," Xiu-Ming Cui," Li Yang," \\ Zhao-Xiang Wu, ${ }^{*}$ Mei-Lan Chen* and Yan Zhang* \\ *National Resource Center for Chinese Materia Medica \\ China Academy of Chinese Medical Sciences \\ Beijing 100700, People's Republic of China \\ ${ }^{\dagger}$ China National Corp. of Traditional and Herbal Medicine \\ Beijing 100195, People's Republic of China \\ tSoil Ecology and Ecosystem Restoration \\ State Key Laboratory of Urban and Regional Ecology \\ Research Center for Eco-Environmental Sciences \\ Chinese Academy of Sciences, Beijing 100085 \\ People's Republic of China \\ \$State Key Laboratory of Earth Surface Processes \\ and Resource Ecology, Beijing Normal University \\ Beijing 100875, People's Republic of China \\ 'Sanqi (Panax notoginseng) Academy of Sciences \\ Wenshan, Yunnan 663000, People's Republic of China
}

\begin{abstract}
Arbuscular mycorrhizal (AM) are symbiotic systems in nature and have great significance in promoting the growth and stress resistance of medicinal plants. During our literature searchfrom the Chinese Scientific Information Database (Chinese National Knowledge Infrastructure, CNKI) we obtained 65 articles with "AM fungi" and "medicinal plant" as the key words, which indicates that in China, research efforts on these topics have been increasing. The main purposes of this review are to discuss the effects of mycorrhiza on the active ingredients of Chinese medicinal plants in comparison with results obtained in other plants in studies conducted by the international research community, and to introduce works published in Chinese journals to international colleagues.
\end{abstract}

Keywords: Arbuscular Mycorrhizal Fungi; Medicinal Plant; China; Sustainable Cultivation; Review.

Correspondence to: Dr. Lu-Qi Huang, National Resource Center for Chinese Materia Medica, China Academy of Chinese Medical Sciences, No. 16 Nanxiaojie, Dongzhimennei, Dongcheng District, Beijing 100700, China. Tel: (+86) 10-6401-1944, Fax: (+86) 10-6401-1944, E-mail: huangluqi@263.net 


\section{Introduction}

Arbuscular mycorrhizal fungi (AMF) constitute a key functional group of soil biota, and contribute greatly to crop productivity and ecosystem sustainability in new plant production strategies (Gianinazzi et al., 2010). AMF can form symbiotic relationships with more than $80 \%$ of the vascular plants on the land. They can improve the growth and development of plants by promoting the absorption of mineral nutrition and by improving the stress resistance abilities of plants. They also can maintain the balance of micro-ecology of the soil, stabilize soil aggregates, and prevent erosion. So the beneficial effects of AMF on plant performance and soil health are essential for the sustainable management of agricultural ecosystems (Jeffries et al., 2003; Barrios, 2007; Smith and Read, 2008).

The knowledge of Traditional Chinese Medicine (TCM) is the wisdom accumulated for thousands of years (Wang et al., 2011a; Xu et al., 2011). Its effectiveness has been recognized by the Chinese people (Wang et al., 2011b; Xutian et al., 2012). The highquality of Chinese herbal medicine is important to ensure the efficacy of TCM (Cai et al., 2011; Chen et al., 2011). In recent years, the dramatic increase in the production and decline in quality of Chinese herbal medicines resulted in a crisis in the development of TCM. The cropping obstacle of medicinal plant cultivation is an important factor affecting the production of Chinese herbal medicines. AMF have positive effects in helping medicinal plants to resist pests, diseases, and adverse environmental stresses and improve yield and quality. Therefore, AMF will help to promote the ecological restoration of cultivated soils of medicinal plants.

Mandala (Datura stramonium L.) and Schizonepeta [Schizonepeta tenuifolia (Benth.) Briq.] are the first two medicinal plants known to be affected by AMF (Wei and Wang, 1989, 1991). It has been shown that AMF promote the accumulation of the effective ingredients of medicinal plants, which has become a hot research area lately (Fig. 1, Chen et al., 2009b). The main purpose of these research is to increase the yield and to improve the quality of medicinal

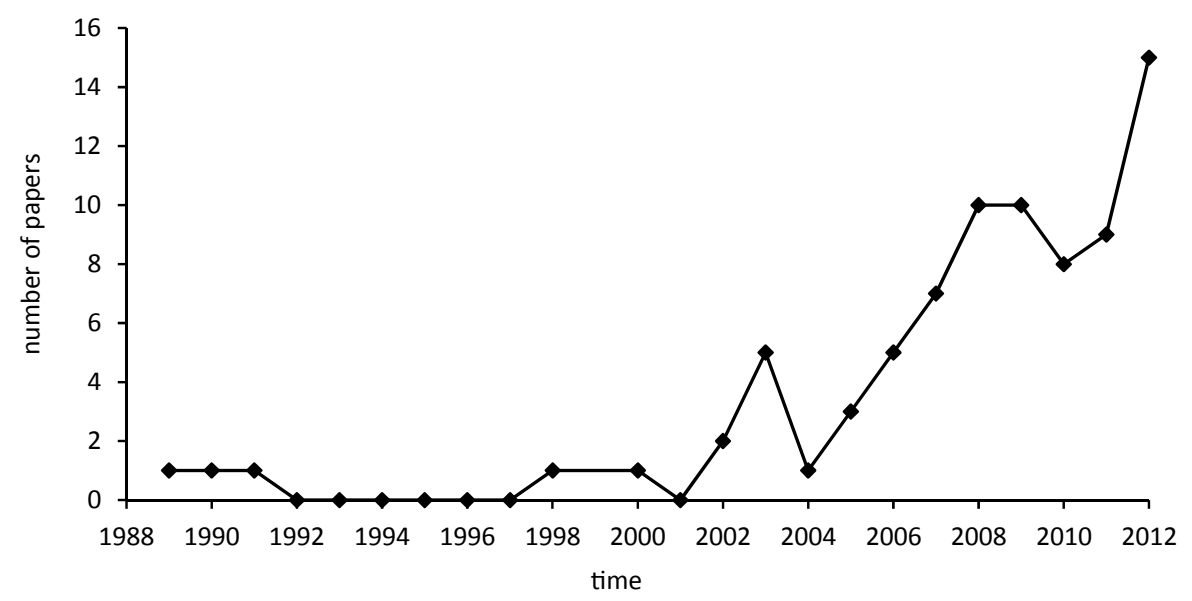

Figure 1. The number of papers on AM and medicinal plant published in China during the past twenty years. 
materials. However, in-depth research is required to understand the mechanisms of the effects of AMF in the accumulation of effective ingredients of medicinal plants (Toussaint, 2007).

The great potential of TCM and the relationship between AMF and the secondary metabolism of medicinal plants have been studied intensively in China and reported in Chinese journals. However, the results of these studies largely remain unknown by researchers worldwide. Therefore, here we summarize the current research progress on the relationship between AMF and medicinal plants in China.

\section{Research on AMF and Medicinal Plants in China for the Past Two Decades}

Research efforts on the relationship between medicinal plants and AMF increased significantly during the past twenty years in China (Fig. 1). The research topics included the resources of AMF, inoculation methods, and the growth, development and secondary metabolites of AMF in association with medicinal plants (Fig. 2). Thirty-five papers were related to the growth and development, stress tolerance, nutrient uptake, and biomass accumulation of medicinal plants in the presence of AMF. Twenty-six papers focused on secondary metabolites of medicinal plants associated with AMF. These metabolites included terpenes (such as total essential oil, sesquiterpene, and diterpenes), alkaloids (such as scopolamine, berberine, and camptothecin), and phenols (such as flavonoids and coumarin). A total of 14 articles focused on the basic biology of AMF and medicinal plants, such as infection process and infection condition.

These studies involved 33 species from 17 families (Table 1), especially medicinal plants such as Salvia miltiorrhiza Bge, Atractylodes macrocephala Koidz., Panax ginseng C. A. Mey., Ginkgo biloba L., and Camptotheca acuminate. Some of them are commonly used medicinal plants in China, such as Panax ginseng C. A. Mey., Panax notoginseng (Burk) F. H. Chen, Salvia miltiorrhiza Bge, Ophiopogon japonicus, Atractylodes macrocephala Koidz., Atractylodes lancea (Thunb) DC., Artemisia Annua L., and Glycyrrhiza

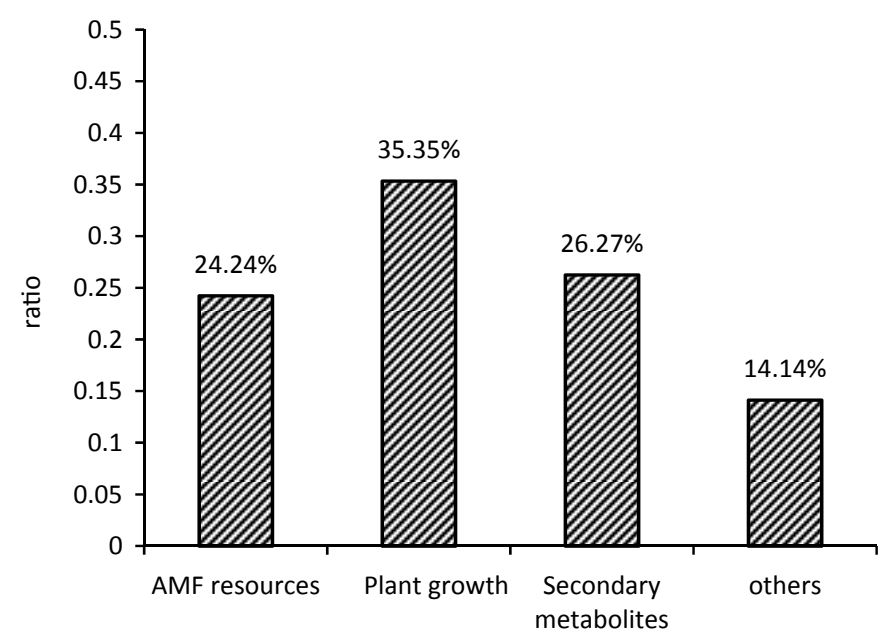

Figure 2. Research on medicinal plant with AM fungi in China during the past twenty years. 
Table 1. The Chinese Medicinal Plants had Taken Research of Mycorrhizal with AM Fungi

\begin{tabular}{l} 
Family \\
\hline Solanaceae \\
Datura stramonium L. (Wei and Wang, \\
1989) \\
Araliaceae \\
Panax ginseng C. A. Mey. (Zhang et al., \\
1990; Xing et al., 2000, 2003; Li, \\
2003a; Cho et al., 2009) \\
Panax notoginseng (Burk) F. H. Chen \\
(Ren et al., 2007; Zhang et al., \\
2011b) \\
Salvia miltiorrhiza Bge (He et al., 2009a, \\
b; Wang and He, 2009; Ma et al., \\
2009; He et al., 2010; Meng and He, \\
2011; He et al., 2012a) \\
Schizonepeta tenuifolia (Benth.) Briq \\
(Wei and Wang, 1991) \\
Bupleuruin scorzonerifolium Willd. \\
(Teng and He, 2005) \\
Scutellaria baicalensis Georgi (Wang \\
et al., 2012a; He et al., 2012b)
\end{tabular}

Mentha arvensis (Gupta et al., 2002)

Mentha viridis (Karagiannidis et al., 2011)

Pogostemon cablin (Blanco) Benth. (Arpana et al., 2008; Rakshapal et al., 2012)

Gentianaceae sp.

Liliaceae

Ginkgoales engler

Gramineae

Nyssaceae
Gentiana manshurica Kitag. (Wang et al., 1998)

Aloe barbadensis Miller (Gong et al., 2002)

Ophiopogon japonicus (Thunb.) Ker-Gawl. (Pang et al., 2008)

Paris polyphylla Smith var. yunnanensis (Franch.) Hand.-Mazz. (Zhou et al., 2009, 2010, 2012)

Ginkgo biloba L. (Qi et al., 2002, 2003; Zhang et al., 2004; Wu and Wei, 2008)

Coix lachrymal-jobi L. var. mayuen (Roman.) Stapf (Li, 2003b)

Camptotheca acuminata (Huang et al., 2003; Zhao and Yan, 2006; Zhao et al., 2006; Yu et al., 2010; Yu and Yan, 2012)

\section{Medicinal Value}

Remove rheumatism, treat cough, alleviate pain

Reinforce vital energy, restore physiological weakness

Remove passive congestion, detumescence, treat pain, hemostasis

Treat irregular menstruation, cardiovascular diseases, hepatitis, and asthma

Treat flu, headache and vomiting

Treat cold and fever, chest pain, irregular menstruation; uterine fall off, rectocele

Treat respiratory tract infection, Lung fever cough, pneumonia, diarrhea, quickening uneasy, hypertension alleviate heat, detoxification

Treat headache, sore throat, mouth sores, toothache alleviate heat, detoxification

Treat headache, sore throat, mouth sores, toothache

Treat abdominal pain, loss of appetite, vomiting, have a headache, fever, tinea

Treat acute icterohepatitis, fever, and convulsions

Antibacterial, anti-inflammatory and enhance immunity

Treat cough, insomnia and constipation

Treat malignant boil and swell, sore of the throat, and trauma

Furit: treat cough and gasp, wet dream, frequency of urination, and hypertension

Treat diarrhea, edema, dermatophytosis, and pulmonary abscess

Camptothecaacuminata used for treatment of tumors 
Table 1. (Continued)

\begin{tabular}{|c|c|c|}
\hline Family & Species & Medicinal Value \\
\hline \multirow[t]{3}{*}{ Asteraceae } & $\begin{array}{l}\text { Atractylodes macrocephala Koidz. } \\
\text { (Lu and He, 2005, 2008; Lu et al., } \\
\text { 2008a,b; Wang et al., 2010; Lu et al., } \\
\text { 2011) }\end{array}$ & $\begin{array}{l}\text { Treat abdominal distension, diarrhea, edema, } \\
\text { spontaneous perspiration, and fetal irrit- } \\
\text { ability }\end{array}$ \\
\hline & $\begin{array}{l}\text { Atractylodes lancea (Thunb) DC. (Guo } \\
\text { et al., 2006; Zhang et al., 2010; } \\
\text { Zhang et al., 2011a) }\end{array}$ & $\begin{array}{l}\text { Treat abdominal fullness and distention, } \\
\text { diarrhea, edema, dermatophytosis, } \\
\text { rheumatism, cold, and nyctalopia }\end{array}$ \\
\hline & $\begin{array}{l}\text { Artemisia Annua L. (Kapoor et al., 2007; } \\
\text { Chaudhary et al., 2008; Rapparini } \\
\text { et al., 2008; Huang et al., 2011) }\end{array}$ & Resist malaria \\
\hline \multirow[t]{3}{*}{ Rutaceae } & $\begin{array}{l}\text { Phellodendron amurense Rupr (Fan } \\
\text { et al., 2006, 2012a,b; Jie et al., } \\
\text { 2007; Cai et al., 2008; Wang et al., } \\
\text { 2012b) }\end{array}$ & Dysentery, detoxicate and cure furuncles \\
\hline & $\begin{array}{l}\text { Phellodendron chinense Schneid (Zhou } \\
\text { and Fang, 2007) }\end{array}$ & Dysentery, detoxicate and cure furuncles \\
\hline & Citrus aurantium L. (Wu et al., 2010) & Promote digestion and increase appetite \\
\hline \multirow[t]{4}{*}{$\begin{array}{l}\text { Leguminosae } \\
\quad \text { sp. }\end{array}$} & $\begin{array}{l}\text { Puerraria lobata (willd.) Ohwi (Wang } \\
\text { et al., 2006) }\end{array}$ & Treat fever, headache, and diarrhea \\
\hline & $\begin{array}{l}\text { Astragalus membranaceus (Liu and } \mathrm{He} \text {, } \\
\text { 2008; He } \text { et al., 2009c) }\end{array}$ & Increase immunity, treat diabetic mellitus \\
\hline & $\begin{array}{l}\text { Glycyrrhiza inflata Bat (Liu and } \mathrm{He} \text {, } \\
\text { 2009) }\end{array}$ & $\begin{array}{l}\text { Clear away toxic materials, eliminate } \\
\text { phlegm, and relieve cough }\end{array}$ \\
\hline & $\begin{array}{l}\text { Glycyrrhiza uralensis Fish (Liu et al., } \\
\text { 2007) }\end{array}$ & $\begin{array}{l}\text { Clear away toxic materials, eliminate } \\
\text { phlegm, and relieve cough }\end{array}$ \\
\hline Oleaceae & $\begin{array}{l}\text { Forsythia suspense (Thunb.) Vahl (Zhao } \\
\quad \text { et al., 2007) }\end{array}$ & $\begin{array}{l}\text { Clear away toxic materials, treat cold, fever, } \\
\text { and sore throat }\end{array}$ \\
\hline Apiaceae & $\begin{array}{l}\text { Angelica dahurica (Fisch.) Benth. } \\
\text { et Hook (Cao and Zhao, 2007; Zhao } \\
\text { et al., 2009, 2011) }\end{array}$ & Treat headache, toothache and nasosinusitis \\
\hline Taxaceae & $\begin{array}{l}\text { Taxus chinensis var. mairei (Ren et al., } \\
\text { 2008) }\end{array}$ & Anti-cancer \\
\hline Araceae & $\begin{array}{l}\text { Pinellia ternate (Thunb.) Breit. (Chen } \\
\text { et al., 2009a, 2010; Guo et al., 2010; } \\
\text { Shen et al., 2011) }\end{array}$ & Treat cough and vomit \\
\hline Ranunculaceae & $\begin{array}{l}\text { Coptis deltoidea C.Y. (Huang et al., } \\
\text { 2012) }\end{array}$ & $\begin{array}{l}\text { Heat-clearing and damp-drying, purging fire } \\
\text { for removing toxin }\end{array}$ \\
\hline \multirow[t]{2}{*}{ Apocynaceae } & $\begin{array}{l}\text { Catharanthus roseus (L.) G. Don } \\
\quad \text { (Rosa-Mera et al., 2011) }\end{array}$ & $\begin{array}{l}\text { Treat hypertension, fire burns, malignant } \\
\text { lymphoma, chorionic carcinoma, } \\
\text { leukemia }\end{array}$ \\
\hline & $\begin{array}{l}\text { Rauwolfia serpentina Benth. (Kaushish } \\
\text { et al., 2012) }\end{array}$ & Treat hypertension \\
\hline
\end{tabular}


inflata Bat. Most medicinal plants have been used for the treatment of diseases and health care. For example, Panax ginseng C. A. Mey. helps to promote energy level and relieve fatigue; Panax notoginseng (Burk) F. H. Chen has detumescence effects, and is able to remove extravasated subcutaneous blood and treat pain; Salvia miltiorrhiza Bge is used to treat irregular menstruation and thrombosis. Some medicinal plants are unique to Chinaand have unique medical effects, such as Panax notoginseng (Burk) F. H. Chen and Paris polyphylla Smith var. yunnanensis (Franch.) Hand. -Mazz.

\section{Resources of AMF Associated with Medicinal Plants}

Resources of AMF associated with medicinal plants are very rich and valuable in China. Many researchers have isolated and/or identified AMF from the rhizosphere of different medicinal plants (Jiang et al., 2012; He et al., 2012c; Jiang and Wang, 2012; Yang et al., 2012a; Zhao et al., 2012). Some AMF have been identified at genus or species levels (Table 2). In addition, researches on the resources of AMF associated with medicinal plants, the relationship between AMF diversity and the growth or quality of medicinal plants, and the selection and production of effective AMF inoculum have contributed to the

Table 2. AMF Resources Identified from the Rhizosphere of Chinese Medicinal Plants

\begin{tabular}{|c|c|}
\hline Species & AMF \\
\hline Gentiana manshurica Kitag. (Wang et al., 1998) & Glomus mosseae, Glomus geosporum \\
\hline Panax ginseng C. A. Mey. (Xing and Li, 2000) & $\begin{array}{l}\text { Acaulospora cavernata, Acaulospora spinosa, Glomus } \\
\text { fasciculatum, Glomus geosporum, Glomus } \\
\text { macrocarpum, Glomus microaggregatum, Glomus } \\
\text { mosseae, Sclerocystis coremioides, Sclerocystis } \\
\text { clavispora, Scutellospora calospora }\end{array}$ \\
\hline Puerraria lobata (willd.) Ohwi (Wang et al., 2006) & Glomus, Acaulosp, Scutellosp \\
\hline $\begin{array}{l}\text { Panax notoginseng (Burk) F. H. Chen (Ren et al., } \\
\text { 2007; Zhang et al., 2011) }\end{array}$ & $\begin{array}{l}11 \text { species of Glomus, } 4 \text { species of Acaulospora: } \\
\text { Acaulospota tuberculata, Acaulospota spinosa, } \\
\text { Acaulospota foveata, Acaulospota denticulate, } \\
\text { Glomus geosporum, Glomus clarum, Glomus } \\
\text { constrictum, Glomus monosporum, Glomus lar- } \\
\text { oideum, Glomus versifome, Glomus microcarpum, } \\
\text { Glomus mosseae, Glomus hoi, Glomus halonatum, } \\
\text { Glomus reticulatum }\end{array}$ \\
\hline Ophiopogon japonicus (Pang et al., 2008) & 10 species of Glomus and Gigaspora \\
\hline $\begin{array}{l}\text { Phellodendron amurense Rupr (Cai et al., 2008; } \\
\text { Wang et al., 2012b) }\end{array}$ & $\begin{array}{l}\text { Glomus intraradices, Glomus mosseae, Scutellospora } \\
\text { calospora }\end{array}$ \\
\hline Taxus chinensis var. mairei (Ren et al., 2008) & $\begin{array}{c}\text { Acaulospora laevis, Glomus versifome, Glomus geos- } \\
\text { porum, Glomus clarum, Glomus costrictum }\end{array}$ \\
\hline $\begin{array}{l}\text { Syringa reticulate var. amurensis, Cercidiphyllum } \\
\text { japonicum, Taxus chinensis var. mairei, Euptelea } \\
\text { pleiosperma (Wang et al., 2008) }\end{array}$ & $\begin{array}{l}27 \text { species of Glomus, Acaulospora, Scutellospora, } \\
\text { Diversispora and Archaeospora }\end{array}$ \\
\hline
\end{tabular}


Table 2. (Continued)

\begin{tabular}{lc}
\hline Species & AMF \\
\hline Salvia miltiorrhiza Bge. (Wang and He, 2009) & 16 species of Glomus, 5 species of Caulospora, \\
& 3 species of Scutellospora, 1 species of Entro- \\
phospora & species of Caulospora, 7 species of Glomus, \\
Paris polyphylla Smith var. yunnanensis (Zhou et al., & 11 species of Gigaspora, 3 species of Scutellospora \\
2009) & 16 species of Glomus, 5 species of Acaulospora, \\
Salvia miltiorrhiza Bge. (He et al., 2010) & 2 species of Scutellospora, 1 species of Entro- \\
& phospora \\
Pinellia ternate (Thunb.) Breit. (Chen et al., 2010) & Glomus mosseae, Glomus intraradices, Glomus \\
& melanosporum, Glomus deserticola, Scutellospora \\
castanea, Gigaspora albida
\end{tabular}

sustainable development of TCM. Further investigations will likely help to bring huge economic and environmental benefits.

\section{Relationship between AMF Resources from the Rhizosphere of Medicinal Plants with Environmental Factors}

The status of infection of AMF on medicinal plants varies because of different soil conditions (Zhao et al., 2012). The rate of AMF colonization is greatly impacted by soil properties such as $\mathrm{pH}$, available phosphorus, and nitrogen in the rhizosphere of Puerraria lobata (willd.) Ohwi (Leguminosae), Salvia miltiorrhiza Bge. (Labiatae), Dioscorea opposite (Dioscoreaceae), Adenophora borealis (Apiaceae), Bupleurum chinense DC. (Apiaceae), and Angelica dahurica (Fisch.) Benth. (Apiaceae) (Wang et al., 2006; Gao and He, 2007; Cao and Zhao, 2007; Wang et al., 2008; Ma et al., 2009; He et al., 2010). Seasonal changes in environmental factors such as soil temperature, humidity, and rhizospheric microorganism, also impacted AMF. It has been found that the spore densities and colonization rates of AMF change with seasons on the medicinal plants Puerraria lobata (willd.) Ohwi and Salvia miltiorrhiza Bge. (Wang et al., 2006; Wang and He, 2009). Wang et al. (2012b) have found that the infection rate, abundance, dominancy and diversity index of the mycorrhizae in urban plantation, natural secondary forest, and natural primary forest are significantly different in different environments. 


\section{AMF Diversity and the Degradation of Medicinal Plant Varieties}

Chen et al. (2010) have found that the spore type and quantity of AMF are richer in Guizhou Province than other provinces, and that the dominant AMF species in the rhizospheres of the wild and cultivated plants of Pinellia ternate (Thunb.) Breit. is quite different. For example, Gigaspora albida only occurs in cultivated plants, and Glomus elanosporum only occurs in the wild plants. The differences in the type, quantity, and dominant species of AMF may be the main causes leading to the degradation of cultivated varieties of Pinellia ternate (Thunb.) Breit. The rate of natural infection is slower in the cultivated medicinal plants than in the wild ones, which may be caused by the excessive use of chemical fertilizers and pesticides (Zhang et al., 1990).

\section{AMF Diversity and Continuous Cultivation of Medicinal Plants}

The continuous cultivation of medicinal plants leads to low AMF diversity in the rhizosphere and an imbalance in soil microbial communities, which destroys the microenvironment of the soil. Spore density and AMF structures are very useful indicators of ecological conditions and the capabilities of plants to form mycorrhiza. The percent of vesicular colonization can be used as an evaluation index of soil conditions to grow medicinal plants (Wang et al., 2006; Ma et al., 2009), or a "diagnostic agent" of soil degradation.

\section{AMF Resources and the Production of Endangered and Precious Chinese Herbal Medicines}

Sanqi [Panax notoginseng (Burk) F. H. Chen] is a precious, unique and bulk Chinese medicinal plant. Zhang et al. (2011) have found that the natural infection rate of sanqi is significantly correlated with its fresh weight. Artificial inoculation experiments in the field have shown that Glomus mosseae and Glomus versiforme significantly improve the biomass of sanqi (Zeng et al., unpublished). So using AMF to improve the production of medicinal plants in cultivation processes is an important and useful technique.

Polyphylla (Paris polyphylla Smith var. yunnanensis) is an endangered and precious medicinal plant mainly distributed in the southwest of China. The average growth cycle for the production of qualified medicinal materials is 6-8 years. Zhou et al. (2009) have identified 24 species of AMF from the rhizosphere of polyphylla. In subsequent studies (Zhou et al., 2010), they have found that the infection rate and spore density are positively correlated with the total steroidal saponins of the roots. Therefore, AMF are likely one of the important factors impacting the production of active ingredients of medicinal plants. It may be beneficial to infect the plant with AMF to enhance the quality and to shorten the growth cycle of polyphylla. Studying valuable and endangered medicinal plants with long growth cycles and their dominant AMF species are important for the conservation and sustainable development of medicinal plant resources. 


\section{AMF Resources, Infection Rate and Development of Exclusive Inoculants of Medicinal Plants}

Based on the results of the investigations on AMF resources, a series of studies have been carried out to study the effects of AMF on the growth and production of effective ingredients of medicinal plants. For example, the natural infection rates of AMF are low in the medicinal plants Coix lachrymal-jobi L., Camptotheca acuminata, Ginkgo biloba L., and Forsythia suspense (Huang et al., 2003; Li, 2003b; Qi et al., 2003; Zhao et al., 2007), but artificial infection may help to achieve unexpected results when the infection rate is increased during inoculation. Many researchers have found a variety of AMF in the rhizospheres of medicinal plants, and some species are present at high levels. These are the advantage species of medicinal plants. For example, Glomus geosporum is the advantage species of Panax notoginseng (Burk) F. H. Chen (Ren et al., 2007), Acaulospora brieticulata is the advantage species of Paris polyphylla Smith var. yunnanensis (Zhou et al., 2009), Scutellospora castanea is the advantage species of Pinellia ternate (Thunb.) Breit. (Chen et al., 2010), and Glomus and Gigaspora are the advantage groups of Ophiopogon japonicus (Pang et al., 2008). If these advantage AMF species have important effects on the growth and quality of medicinal plants, they have great potential to be used as the exclusive AMF inoculum for the specific medicinal plants they are associated with. Therefore, the research on AMF diversity and advantage species of medicinal plants are important research areas to pursue in order to further understand the ecology of medicinal plants and AMF and the effects of AMF on the growth and quality of medicinal plants.

\section{Impacts of AM Symbiosis on the Growth, Development and Resistance of Medicinal Plants}

The biomass of medicinal plants is greatly affected by their growth, development, and disease status, which have been shown to be related to AMF (Table 3). AMF help plants to improve the absorption of mineral nutrition and promote growth. Generally they promote the absorption of $\mathrm{P}, \mathrm{N}, \mathrm{Mg}, \mathrm{Na}, \mathrm{Fe}, \mathrm{Mn}, \mathrm{Cu}, \mathrm{Zn}, \mathrm{S}$ and other mineral elements by increasing their affinities, reducing the critical concentration of absorption, producing hyphae secretions, increasing absorption area, and shortening the diffusion area (Smith and Read, 2008). Wei and Wang (1989) are the pioneers in China who have studied the relationship between medicinal plants and AMF. They have found that AMF promote the absorption of $\mathrm{P}$ and $\mathrm{S}$ in pot experiments performed in the greenhouse. Other similar studies have also shown that AMF help to increase the content of total N, total P and total $\mathrm{K}$ in Atractylodes macrocephala Koidz. and Salvia miltiorrhiza Bge. (Lu et al., 2008b, 2011; He et al., 2009a; Wang et al., 2010; Meng and He, 2011; Huang et al., 2011), and that AMF promote the nutrient absorption of Atractylodes lancea (Thunb) DC. (Guo et al., 2006).

After forming a symbiotic relationship with medicinal plants, AMF improve the microenvironment of the soil and plant resistance, promote growth and development, reduce morbidity, increase tolerance for salt and drought, and reduce the stress of heavy metals 
Table 3. Effects of AMF on the Growth of Chinese Medicinal Plants

\begin{tabular}{ll}
\hline Species & Effect on Growth
\end{tabular}

Datura stramonium L.
Schizonepeta tenuifolia
(Benth.) Briq.
Aloe barbadensis Miller
Ginkgo biloba L.
Panax ginseng C. A. Mey.
Coix lachrymal-jobi L.
var. mayuen (Roman.)
Stapf
Amptotheca acuminata
Atractylodes macrocephala
Koidz.

Atractylodes lancea

(Thunb) DC.

Forsythia suspense (Thunb.) Vahl

Phellodendron chinense Schneid

Angelica dahurica (Fisch. ex Hoffm.)

Benth. et Hook. f.

Salvia miltiorrhiza Bge.

Astragalus membranaceus

Glycyrrhiza inflata Bat
Improves plant growth, increases the uptake of phosphorus, sulphur and other elements (Wei and Wang, 1989)

Significantly improves plant growth and the uptake of P, S, K, Na, $\mathrm{Fe}, \mathrm{Mo}, \mathrm{Mn}, \mathrm{Zn}, \mathrm{Co}, \mathrm{Ba}, \mathrm{Ni}$, and Pb (Wei and Wang, 1991)

Seedling height and leave length increase significantly (Gong et al., 2002)

Seedling height, leaf area, dry mass of leaf and root, dry biomass of leaf, chlorophyll content in leaf, activity of root are significantly improved by AM colonization. The disease index is significantly reduced (Qi et al., 2002, 2003)

Survival rate, seed yield, production of the medicinal material, and quality of single plant are significantly improved with AM colonization (Li, 2003a; Cho et al., 2009)

Plant height, tillering number, weight of one hundred seeds and yield are increased with AM colonization (Li, 2003b)

Total biomass increases significantly (Huang et al., 2003; Zhao and Yan, 2006)

Soluble sugar, soluble protein, activities of the protective enzymes, content of photosynthetic pigments, total content of $\mathrm{N}$, length of root, height of plant, total dry weight of the plants are improved significantly (Lu and He, 2005, 2008; Lu et al., 2008a,b; 2010, 2011; Wang et al., 2010)

AM promote nutrition uptake, improve the function diversity and activity of microbes in rhizosphere of the plant. The height of plant, numbers of leaves and leaf area total biomass are improved significantly (Guo et al., 2006; Zhang et al., 2010, 2011)

Seedlings inoculated with AM are more drought resistant because they rapidly accumulate free proline, enhance the activity of SOD, and reduce the level cell membrane damages, (Zhao et al. 2007)

Height and biomass of seeding are improved significantly (Zhou and Fan, 2007).

Plants inoculated with AM have significantly increased biomass and high levels of chlorophyll, carotenoids, soluble sugar, and soluble protein of MDA (Zhao et al., 2009, 2011)

Inoculating AM could increase the biomass, soluble sugar and chlorophll in leaves, $\mathrm{P}$ of the root, total $\mathrm{N}$ of the plant. strengthening the drought resistance of the plant (He et al., 2009a, 2012a,b; Meng and He, 2011)

Significantly improves growth and increases the biomass; improves soluble protein and sugar contents, as well as SOD, POD and CAT activities (He et al., 2009c)

AM improves metabolic activity and the activities of protective enzymes of mycorrhizal plants (Liu and He, 2009) 
Table 3. (Continued)

\begin{tabular}{|c|c|}
\hline Species & Effect on Growth \\
\hline $\begin{array}{l}\text { Pinellia ternate (Thunb.) } \\
\quad \text { Breit. }\end{array}$ & $\begin{array}{l}\text { Propagation efficiency and yield are increased, while seeding lod- } \\
\text { ging time Is delayed in plants inoculated with AM (Guo et al., } \\
\text { 2010) }\end{array}$ \\
\hline Citrus aurantium $\mathrm{L}$. & $\begin{array}{l}\text { Shoot fresh weight, root fresh weight, soluble protein content, and } \\
\text { activities of SOD and CAT in roots under } \mathrm{NaCl} \text { stress are } \\
\text { enhanced in plants inoculated with } \mathrm{AM} \text { (Wu et al., 2010) }\end{array}$ \\
\hline Artemisia аппиа $\mathrm{L}$. & $\begin{array}{l}\text { The uptake of N, P, K, Zn, Fe, chlorophyll content, photosynthesis } \\
\text { and biomass are significantly improved in plants inoculated with } \\
\text { AM (Kapoor et al., 2007; Chaudhary et al., 2008; Huang et al., } \\
\text { 2011) }\end{array}$ \\
\hline $\begin{array}{l}\text { Phellodendron amurense } \\
\quad \text { Rupr. }\end{array}$ & $\begin{array}{l}\text { Inoculation with } G \text {. mosseae and } G \text {. diaphanum would promote the } \\
\text { height, basal diameters, fresh weights and dry weights of } \\
\text { seeding and would improve the survival rate significantly. It can } \\
\text { also enhance the absorb of nitrogen. (Fan et al., 2012, 2012b) }\end{array}$ \\
\hline Scutellaria baicalensis Georgi & $\begin{array}{l}\text { The uptake of nitrogen, phosphorus, calcium, ferrum are signifi- } \\
\text { cantly improved in plants inoculated with AM (Wang et al., } \\
\text { 2012a) }\end{array}$ \\
\hline Metha arvensis & $\begin{array}{l}\text { Significantly increase the growthand nutrient acquisition (Gupta } \\
\text { et al., 2002) }\end{array}$ \\
\hline $\begin{array}{l}\text { Mentha viridis (Karagiannidis } \\
\quad \text { et al., 2011) }\end{array}$ & $\begin{array}{l}\text { Significantly increase the growth and nutrient acquisition (Kar- } \\
\text { agiannidis et al., 2011) }\end{array}$ \\
\hline Glycyrrhiza uralensis Fish & $\begin{array}{l}\text { Significantly improve the plant growth and phosphorus acquisition } \\
\text { (Liu et al., 2007) }\end{array}$ \\
\hline Pogostemon cablin (Blanco) Benth. & $\begin{array}{l}\text { Significantly improve the plant height, number of branches/spread } \\
\text { and biomass (Arpana et al., 2008; Rakshapal et al., 2012) }\end{array}$ \\
\hline Rauwolfia serpentina Benth. & $\begin{array}{l}\text { Improve the content of phosphorus, chlorophyll and stomatal con- } \\
\text { ductivity (Kaushish et al., 2012) }\end{array}$ \\
\hline
\end{tabular}

(Smith and Read, 2008; Yang et al., 2012b). For example, the activity of the root of ginkgo seedlings (Ginkgo biloba L.) is increased, and the disease index of ginkgo leaf blight is significantly reduced in the presence of AMF (Qi et al., 2002, 2003). Inoculation with $G$. mosseae and $G$. diaphanum promotes the height, basal diameter, fresh weight and dry weight of seeding, and improves the survival rate significantly (Fan et al., 2012a,2012b). The disease incidence rate of ginseng (Panax ginseng C. A. Mey.) is reduced and the survival rate is increased significantly after AMF inoculation ( $\mathrm{Li}, 2003 \mathrm{a})$. AMF also play a role in delaying the lodging time of Pinellia seedling [Pinellia ternate (Thunb.) Breit.] (Guo et al., 2010). The hypha of AMF help with the absorption of mineral elements and soil water in the mycorrhizal plant. In plant infected with AMF, the metabolic activities and the protective enzyme activities are improved to strengthen drought resistance of Glycyrrhiza inflata Bat and Salvia miltiorrhiza Bge. (Liu and He, 2009; Meng and He, 2011). In Forsythia suspense, seedlings infected with AMF are anti-drought through the accumulation of free proline and the elevation of SOD activity, as well as the reduction of cell membrane damages (Zhao et al., 2009). Angelica dahurica plants inoculated with AMF also have high contents of chlorophyll, carotenoids, soluble sugar and soluble 
protein, low contents of MDA and proline, and increased activities of superoxide dismutase and peroxidase in the leaves, which result in drought resistance (Zhao et al., 2011) The seedlings of Citrus aurantium L. inoculated with AMF are more salt resistant, and have higher soluble protein content, SOD activity and CAT activity in the roots than noninoculated seedlings (Wu et al., 2010). AMF help medicinal plants to reduce the absorption of heavy metals. Wei and Wang (1989) have found that Datura stramonium L. plants inoculated with AMF have low contents of lead and cadmium.

The impact of symbiosis on medicinal plants is related to soil fertility, quality of fertilizers used (Lu and He, 2005, 2008; Lu et al., 2008a,b, 2011; He et al., 2009c; Wang et al., 2010), and AMF species (Wei and Wang, 1989, 1991; Huang et al., 2011). Researchers have found that medicinal plants inoculated with mixed AMF have higher fresh weight, dry weight, and propagation efficiency than those inoculated with a single AMF (Guo et al., 2010).

Under poor soil conditions, AMF promote the growth and increase the biomass of most plants. It is necessary to perform researches under environmental conditions inherent with those of the cultivation area in order to obtain the ideal conditions under which AMF promote the growth of medicinal plants.

In the conditions of a given soil and climate, proper control of the environmental factors by artificial means based on the use of agricultural facilities are required to provide more favorable conditions for the symbiosis between the medicinal plants and AMF, and to obtain robust and seedlings with resistance. The main goal in the cultivation of TCM is to increase production of the medicinal plants while reducing the use of chemical fertilizers and pesticides. The use of AMF will be helpful to achieve this goal.

\section{Active Ingredients of Medicinal Plants and AM Symbiosis}

The active ingredients of TCM are usually secondary metabolites of medicinal plants and are the key substances in treating diseases. Until now, the research direction with the highest priority was to promote the content of secondary metabolites of medicinal plants. More than 20 reports have shown the positive effects of AM on secondary metabolite production, including terpenes (such as total essential oil, sesquiterpene, and diterpenes), alkaloids (such as scopolamine, berberine, and camptothecin), and phenols (such as flavonoids and coumarin) (Table 4). Some researches have shown no effect of AM on the production of essential oil, although the total biomass is increased (Guo et al., 2006; Zhang et al., 2010, 2011).

Terpenes consist of isoprene. It has been found that the contents of some isoprenoid derivatives are high in plants associated with AM, which is obviously related to the secondary metabolisms of the plants. Essential oil produced by medicinal plants is a mixture of terpenoids, and is often the active ingredients of herbal medicines. It has been shown that AMF promote the accumulation of essential oil in medicinal plants. For example, AM symbiosis is related to the increase in the synthesis of essential oils in Schizonepeta tenuifolia (Benth.) Briq. (Wei and Wang, 1991), Atractylodes macrocephala Koidz. (Lu et al., 2011), Artemisia Annua L. (Huang et al., 2011), and Atractylodes lancea (Thunb) DC. (Guo et al., 2006; Zhang et al., 2010, 2011a). 
Table 4. Effects of AMF on the Production of Active Ingredients in Chinese Medicinal Plants

\begin{tabular}{|c|c|c|}
\hline Family & Species & Secondary Metabolites Reference \\
\hline Solanaceae & Datura stramonium $\mathrm{L}$. & $\begin{array}{l}\text { Increases the concentrations of hyoscyamine } \\
\text { and hyoscine significantly (Wei and } \\
\text { Wang, 1989) }\end{array}$ \\
\hline \multirow[t]{7}{*}{ Labiatae } & Schizonepeta tenuifolia (Benth.) Briq & $\begin{array}{l}\text { Increases the concentration of essential oil } \\
\text { significantly (Wei and Wang, 1991) }\end{array}$ \\
\hline & Bupleuruin scorzonerifolium Willd. & $\begin{array}{l}\text { Increases the concentration of flavonoid } \\
\text { significantly (Teng and He, 2005) }\end{array}$ \\
\hline & Salvia miltiorrhiza Bge. & $\begin{array}{l}\text { Increases the concentration of tanshinone } \\
\text { significantly (He et al., 2009a, 2012a; } \\
\text { Meng and He, 2011) }\end{array}$ \\
\hline & Scutellaria baicalensis Georgi & $\begin{array}{l}\text { Increases the concentration of baicalin } \\
\text { significantly (Wang et al., 2012a,b) }\end{array}$ \\
\hline & Metha arvensis & $\begin{array}{l}\text { Significantly increase theessential oil yield } \\
\text { (Gupta et al., 2002) }\end{array}$ \\
\hline & Mentha viridis & $\begin{array}{l}\text { Significantly increase theessential oil yield } \\
\quad \text { (Karagiannidis et al., 2011) }\end{array}$ \\
\hline & Pogostemon cablin (Blanco) Benth. & $\begin{array}{l}\text { Significantly increase the essential oil content } \\
\text { (Arpana et al., 2008); enhanced the con- } \\
\text { tent of patchouli alcohol (Rakshapal } \\
\text { et al., 2012) }\end{array}$ \\
\hline \multirow[t]{2}{*}{ Liliaceae } & Aloe barbadensis Miller & $\begin{array}{l}\text { Increases the concentration of active ingre- } \\
\text { dient significantly (Gong et al., 2002) }\end{array}$ \\
\hline & $\begin{array}{l}\text { Paris polyphylla Smith var. yunna- } \\
\text { nensis (Franch.) Hand. -Mazz. }\end{array}$ & $\begin{array}{l}\text { Positive correlation between infection and } \\
\text { steroidal saporin content in root (Zhou } \\
\text { et al., 2010, 2012) }\end{array}$ \\
\hline Ginkgoales engler & Ginkgo biloba $\mathrm{L}$. & $\begin{array}{l}\text { Significant positive correlation between } \\
\text { infection and flavonoid content in root } \\
\text { (Zhang et al., 2004) }\end{array}$ \\
\hline \multirow[t]{2}{*}{ Rutaceae } & Phellodendron amurense Rupr & $\begin{array}{l}\text { Increases the concentrations of berberine, } \\
\text { jatrorrhizine and palmatine significantly } \\
\text { (Fan et al. 2006) }\end{array}$ \\
\hline & Phellodendron chinense Schneid & $\begin{array}{l}\text { increases the concentration of berberine sig- } \\
\text { nificantly (Zhou and Fang, 2007) }\end{array}$ \\
\hline Apiaceae & Angelica dahurica & $\begin{array}{l}\text { Increases the concentrations of total cou- } \\
\text { marin and imperarorin significantly } \\
\text { (Zhao et al., 2009; Zhao et al., 2011) }\end{array}$ \\
\hline \multirow[t]{2}{*}{ Leguminosae sp. } & Astragalus membranaceus, & $\begin{array}{l}\text { Increases the concentration of flavonoid } \\
\text { significantly (He et al. 2009c) }\end{array}$ \\
\hline & $\begin{array}{l}\text { Glycyrrhiza uralensis } \\
\text { Fish }\end{array}$ & $\begin{array}{l}\text { significantly improve the glycrrrhizin con- } \\
\text { centration (Liu et al., 2007) }\end{array}$ \\
\hline Araceae & Pinellia ternate (Thunb.) Breit & $\begin{array}{l}\text { Increases the concentrations of guanosine } \\
\text { and alkaloid significantly (Guo et al., } \\
\text { 2010) }\end{array}$ \\
\hline Nyssaceae & Camptotheca acuminata & $\begin{array}{l}\text { Increases the concentration of camptothecin } \\
\text { significantly (Yu et al., 2010, 2012) }\end{array}$ \\
\hline
\end{tabular}


Table 4. (Continued)

\begin{tabular}{|c|c|c|}
\hline Family & Species & Secondary Metabolites Reference \\
\hline \multirow[t]{3}{*}{ Compositae } & Atractylodes lancea (Thunb)DC. & $\begin{array}{l}\text { No effect on the content of essential oil (Guo } \\
\text { et al., 2006; Zhang et al., 2010, 2011a) }\end{array}$ \\
\hline & Atractylodes macrocephala Koidz. & $\begin{array}{l}\text { Increases the concentration of essential oil } \\
\text { significantly (Lu et al., 2011) }\end{array}$ \\
\hline & Artemisia Аппиа L. & $\begin{array}{l}\text { Increases the concentrations of artemisinin } \\
\text { and essential oil significantly (Kapoor } \\
\text { et al., 2007; Chaudhary et al., 2008; } \\
\text { Huang et al., 2011) }\end{array}$ \\
\hline Apocynaceae & Catharanthus roseus (L.) G. Don & $\begin{array}{l}\text { Induced the accumulation of vinblastine in } \\
\text { leaves (Rosa-Mera et al., 2011) }\end{array}$ \\
\hline
\end{tabular}

It is believed that AMF can induce the production of phenolic compounds in plants and lead to the thickening of the cell wall, which is the natural barrier against bacterial invasion (Volpin et al., 1994; Harrison, 1999). Phenolic compounds, such as flavonoids and coumarin, are the active ingredients in many medicinal plants. Researchers have found that the content of flavonoids in Bupleurum chinense, Salvia miltiorrhiza Bge., Ginkgo biloba L., Astragalus membranaceus and Scuteliaria baiealensis Georgi (Zhang et al., 2004; Teng and He, 2005; He et al., 2009a; He et al., 2009c; Meng and He, 2011; Wang et al., 2012a), and the content of total coumarin and imperatorin in Angelica dahurica (Zhao et al., 2009; 2011) are significantly higher when they are associated with AMF.

The synthesis of plant alkaloids can be induced by exogenous biological stimuli, which may be related to stress and the defense response, because alkaloids are able to reduce the damages. AM symbiosis induces the production of hyoscyamine and scopolamine in Datura stramonium L. (Wei and Wang, 1989). Seedlings associated with AMF have higher contents of berberine, jatrorrhizine and palmatine in Phellodendron amurense Rupr (Fang et al., 2006), a higher content of berberine in Phellodendron chinense Schneid (Zhou and Fang, 2007), a higher content of alkaloids in Pinellia ternate (Guo et al., 2010), and accumulate more camptothecin in Camptotheca acuminate (Yu et al., 2010, 2012).

Plant secondary metabolism has important ecological roles, such as defending plant diseases and insect pests, communicating with other organisms and preventing UV damages. Different secondary metabolites have different ecological functions. Some plants produce alkaloids to prevent the attack of microorganisms, pests and animals (Bennett and Wallsgrove, 1994). Others produce terpenoids to kill herbivorous insects and prevent insect feeding (Harborne, 1999). In addition, secondary metabolites from medicinal plants are also being exploited to treat human diseases.

\section{Discussion}

AMF have been found to enhance biomass, improve disease resistance, increase heavy metal and salinity tolerance, stimulate photosynthesis, as well as influence the level of 
secondary metabolites in plants (Smith and Read, 2008). Therefore, the biotechnological use of AMF have been proposed for agriculture (Hamel, 1996) and endangered plants (Gemma et al., 2002; Turnau and Haselwandter, 2002; Zubek et al., 2008, 2009).

The general purpose of studying medicinal plants is to obtain high-quality materials for the pharmaceutical industry, to achieve significant economic benefits, and to broaden the knowledge of biology and ecology of these valuable plant species. Because there are needs to develop herb varieties and to produce healthy medicinal plants with increased levels of active compounds, the exploitation of AM symbiosis can greatly benefit the herbal industry.

Besides literature that have been published in China, many research papers on the relationship between AMF and medicinal plants are published in SCI journals that are well known by the Chinese people. For example, AMF enhance the growth of Panax ginseng seeding and Rauwolfia serpentina Benth. (Cho et al., 2009; Kaushish et al., 2012), improve the growth and production of essential oils of Mentha viridis (Karagiannidis et al., 2011), induce the accumulation of vinblastine in leaves of Catharantus roseus (Rosa-Mera et al., 2011), and increase the biomass and content of patchouli alcohol or essential oil of Pogostemon cablin. (Arpana et al., 2008; Rakshapal et al., 2012). Many researchers have found the beneficial effect of microbials and believe that it would be conducive to the TCM industry. Gupta et al. (2002) have investigated the effects of AM on Mentha arvensis under field conditions, and shown that AMF significantly enhance the yield of essential oil under field conditions. They believe that AMF can increase the licorice pharmic quality to enhance plant growth and glycyrrhizin accumulation of Glycyrrhiza uralensis Fish (Liu et al., 2007). The synthesis of artemisinin is not yet commercially feasible, therefore increasing the yield of naturally occurring artemisinin is an important area of investigation. Researchers believe that biotechnology can help to improve the biomass and the concentration of artemisinin in Artemisia annua L. (Kapoor et al., 2007; Chaudhary et al., 2008).

The effects of AMF on the biochemical pathways of the host plants have attracted great attention worldwide (Copetta et al., 2006; Toussaint, 2007; Zubek and aszkowski, 2009). Many plants are considered as medicinal raw materials and food additives (e.g. spices). AMF influence the concentrations of several groups of plant metabolites such as alkaloids (Abu-Zeyad et al., 1999; Rojas-Andrade et al., 2003), terpenoids (Akiyama and Hayashi, 2002; Kapoor et al., 2002a,b, 2007; Copetta et al., 2006; Jurkiewicz et al., 2010), carotenoids (Fester et al., 2002), flavonoids (Larose et al., 2002), glucosinolates (Vierheilig et al., 2000), and phenolic acids (Toussaint et al., 2007; Jurkiewicz et al., 2010).

The mechanisms by which AMF trigger changes in the concentration of phytochemicals in plant tissues have been studied but are not yet well understood (Toussaint, 2007). First, secondary metabolites are likely the signal substances between the plant and AMF when symbiosis establishes. Therefore, AMF cause changes in the secondary metabolism of the plant (Larose et al., 2002; Toussaint, 2007). During AMF infection, the plant defensive reactions are also activated against invasion. The production of essential oils, phenolic compounds and terpenoids are actions against fungal infection and colonization (Copetta et al., 2006). Second, AM symbiosis promotes the absorption of $\mathrm{P}, \mathrm{N}$ and other mineral 
nutritients, and thus contributes to the accumulation of secondary metabolites of the plant. For example, isoprenoid biosynthesis requires acetyl-CoA, ATP and NADPH, and is dependent on the concentration of inorganic phosphorus in the plant, so the terpenoid derivative essential oils are enhanced through the absorbance of $\mathrm{P}$ (Loomis et al., 1972). Tyrosine and phenylalanine are important precursors of some secondary metabolites, such as rosmarinic and caffeic acids (Petersen and Simmonds, 2003). Therefore, AM symbiosis enhances the synthesis of certain amino acids by promoting $\mathrm{N}$ absorbance and thus contributes to the accumulation of specific metabolites (Smith and Read, 1997; Toussaint et al., 2004). Third, it is believed that the symbiosis of AM results in the increase of terpenoids and phenolic acids, which may be the result of increased absorption of mineral nutritients especially P and N (Kapoor et al., 2002a,b; Toussaint et al., 2007). Finally, it is likely that the changes in secondary metabolism plants are a result of cytokinins or gibberellin changes (Allen et al., 1980, 1982; Copetta et al., 2006; Kapoor et al., 2007; Toussaint, 2007). But these possibilities all remain to be tested (Toussaint, 2007).

\section{Research Prospects}

This article introduced some examples of the relationship between AMF and medicinal plants published in Chinese journals. These results are difficult for the researchers in other countries to access. Many researches have shown that AMF benefit the growth of medicinal plants by increasing the levels of secondary metabolites in medicinal plants. However, the mechanisms by which AMF trigger changes in the levels of active ingredients in medicinal plants remain unknown. We hope to enhance the concentration of active ingredients in medicinal plants using AMF, which are important to the TCM industry. It has become a consensus that AMF promote the biomass of medicinal plants, especially under poor soil conditions. It is favorable to improve the contents of secondary metabolites of medicinal plants, although some researches have shown that the content of essential oil remain unchanged (Guo et al., 2006; Zhang et al., 2010, 2011; Binet et al., 2011). However, with the improvement in plant biomass, the total yield of essential oil is still enhanced.

The promotion of AMF to secondary metabolism in medicinal plant also has specificity. Khaosaad et al. (2006) have observed that G. mosseae has no effect on the composition of essential oils in three Origanum vulgare L. genotypes; however, the total essential oil contents in two other genotypes are increased with AMF inoculation. Furthermore, there is AMF species specificity in promoting flavonoid production in M. sativa (Larose et al., 2002) and phenolic acid production in O. basilicum (Toussaint et al., 2007). So it is important to study specific strains that have significant effects in improving biomass and the levels of effective components.

The following aspects will likely become the key research directions in the future: (1) Excavation of efficient local AMF strains; (2) Massive production of AMF inoculum for medicinal plants; (3) Medicinal plants seedling production with mycorrhiza; (4) Intensive cultivation of medicinal plants and the production of organic medicinal materials; and (5) Mechanisms by which AMF changes the content of active ingredient in medicinal plants. 


\section{Acknowledgments}

This study was supported by the National Natural Science Foundation of China (NSFC) (81130070, 81072989, 41101245), Special research of industry by State Administration of TCM project (201107009), International technical cooperation projects (2009DFA31660), Projects of science and technology plan of Yunnan Province(2008IF025-4) and the Research Projects of China Academy of Chinese Medical Sciences (ZZ20090302).

\section{References}

Abu-Zeyad, R., A.G. Khan and C. Khoo. Occurrence of arbuscular mycorrhiza in Castanospermum australe A. Cunn. and C. Fraser and effects on growth and production of castanospermine. Mycorrhiza 9: 111-117, 1999.

Akiyama, K. and H. Hayashi. Arbuscular mycorrhizal fungus-promoted accumulation of two new triterpenoids in cucumber roots. Biosci. Biotechnol. Biochem. 66: 762-769, 2002.

Allen, M.F., T.S. Moore and M. Christensen. Phytohormone changes in Bouteloua gracilis infected by vesicular-arbuscular mycorrhizae. I. Cytokinin increases in the host plant. Can. J. Bot. 58: 371-374, 1980.

Allen, M.F., T.S. Moore and M. Christensen. Phytohormone changes in Bouteloua gracilis infected by vesicular-arbuscular mycorrhizae. II. Altered levels of gibberellin-like substances and abscisic acid in the host plant. Can. J. Bot. 60: 468-471, 1982.

Arpana, J., D.J. Bagyaraj, E.V.S. Prakasa Rao, T.N. Parameswaran and B.A. Abdul Rahiman. Symbiotic response of Patchouli [Pogostemon cablin (Blanco) Benth.] to different arbuscular mycorrhizal fungi. Adv. Environ. Biol. 2: 20-24, 2008.

Barrios, E. Soil biota, ecosystem services and land productivity. Ecol. Econ. 64: 269-285, 2007.

Bennett, R.N. and R.M. Wallsgrove. Secondary metabolites in plant defence mechanisms. New Phytol. 127: 617-633, 1994.

Binet, M.N., D. Van Tuinen, N. Deprêtre, N. Koszela, C. Chambon and S. Gianinazzi. Arbuscular mycorrhizal fungi associated with Artemisia umbelliformis Lam, an endangered anomatic species in Southern French Alps, influence plant P and essential oil contents. Mycorrhiza 21: 523-535, 2011.

Cai, B.Y., W.G. Jie, J.P. Ge and X.F. Yan. Molecular detection of the arbuscular mycorrhizal fungi in the rhizosphere of Phellodendron amurense. Mycosystema 27: 884-893, 2008.

Cai, C.C., M.C. Yan, H. Xie and S.L. Pan. Simultaneous determination of ten active components in 12 Chinese Piper species by HPLC. Am. J. Chin. Med. 39: 1043-1060, 2011.

Cao, D.X. and J.L. Zhao. The investigation of arbuscular mycorrhizal fungi and soil factors from the rhizospere of medicinal plant Angelica dahurica. Acta Agric. Bor.-Sin. 22: 47-50, 2007.

Chaudhary, V., R. Kapoor and A.K. Bhatnagar. Effectiveness of two arbuscular mycorrhizal fungi on concentrations of essential oil and artemisinin in three accessions of Artemisia annua L. Appl. Soil Ecol. 40: 174-181, 2008.

Chen, C.Y., J.X. Chen, W. Li, H. Li and B. Yang. Comparative chemical and statistical analysis of cultivated and wild Radix Scutellariae. Am. J. Chin. Med. 39: 1029-1041, 2011.

Chen, L.T., Q.S. Guo and Z.Y. Liu. Infection pattern and dynamic change of arbuscular mycorrhizal fungi in Pinellia ternate. Guizhou Agric. Sci. 37: 37-39, 2009a.

Chen, L.T., Q.S. Guo and Z.Y. Liu. Arbuscular mycorrhiza of cultivated and wild Pinellia ternate. Chin. J. Chin. Mater. Med. 35: 405-410, 2010.

Chen, L.T., Z.Y. Liu, Q.S. Guo and G.S. Zhu. Advances in studies on arbuscular mycorrhizas in medicinal plants. Chin. Tradit. Herbal Drugs 40: 156-160, $2009 \mathrm{~b}$. 
Cho, E.J., D.J. Lee, C.D. Wee, H.L. Kim, Y.H. Cheong, J.S. Cho and B.K. Sohn. Effects of AMF inoculation on growth of Panax ginseng C.A. Meyer seedlings and on soil structures in mycorrhizosphere. Sci. Hortic. 122: 633-637, 2009.

Copetta, A., G. Lingua and G. Berta. Effects of three AM fungi on growth, distribution of glandular hairs, and essential oil production in Ocimum basilicum L. var. Genovese. Mycorrhiza 16: 485-494, 2006.

Fan, J.H., Y.D. Zou, Q.S. Guo and G.L. Li. Comparison of AM fungi on the infection characteristics to Amur Cork tree seeding. Chin. Agr. Sci. Bull. 28: 21-26, 2012.

Fan, J. and J.H. Fang. Effects of mycorrhiza on content of nitrogen and nitrogenous matter of Amur Cork tree. J. Anhui Agri. Sci. 40: 11672-11674, 2012.

Fan, J.H., G.T. Yang, L.Q. Mu and J.H. Zhou. Effect of AMF on the content of Berberine, Jatrorrhizine and Palmatine of Phellodendron amurense seedings. Prot. Forest Sci. Technol. 5: 2426, 2006.

Fester, T., D. Schmidt, S. Lohse, M.H. Walter, G. Giuliano, P.M. Bramley, P.D. Fraser, B. Hause and D. Strack. Stimulation of carotenoid metabolism in arbuscular mycorrhizal roots. Planta 216: 148-154, 2002.

Gao, A.X. and X.L. He. Ecological study on AM fungi around roots of medicinal plants in the middle area of Hebei province. Agric. Res. Arid. Areas 25: 196-202, 2007.

Gemma, J.N., R.E. Koske and M. Habte. Mycorrhizal dependency of some endemic and endangered Hawaiian plant species. Am. J. Bot. 89: 337-345, 2002.

Gianinazzi, S., A. Gollotte, M.N. Binet, D.V. Tuinen, D. Redecker and D. Wipf. Agroecology: the key role of arbuscular mycorrhizas in ecosystem services. Mycorrhiza 20: 519-530, 2010.

Gong, M.Q., F.Z. Wang and Y. Chen. Study on application of arbuscular-mycorrhizas in growing seedling of Aloe vera. J. Chin. Med. Mater. 25: 1-3, 2002.

Guo, L.P., H.G. Wang and L.Q. Hang. Effects of arbuscular mycorrhizae on growth and essential oil of Atractylodes lancea. Chin. J. Chin. Mater. Med. 31: 1491-1495, 2006.

Guo, Q.S., L.T. Chen and Z.Y. Liu. Study on influence of arbuscular mycorrhizal fungi Pinellia ternata yield and chemical composition. Chin. J. Chin. Med. 35: 333-338, 2010.

Gupta, M.L., A. Prasad, M. Ram and S. Kumar. Effect of the vesicular - arbuscular mycorrhizal (VAM) fungus Glomus fasciculatum on the essential oil yield related characters and nutrient acquisition in the crops of different cultivars of menthol mint (Mentha arvensis) under field conditions. Bioresour. Technol. 81: 77-79, 2002.

Hamel, G. Strategy as revolution. Harvard Bus Rev. 74: 69-71, 1996.

Harborne, J.B. Recent advances in chemical ecology. Nat. Prod. Rep. 16: 509-523, 1999.

Harrison, M. Molecular and cellular aspects of the arbuscular mycorrhizal symbiosis. Annu. Rev. Plant Biol. 50: 361-389, 1999.

He, X.L., J. Li, A.X. Gao, L.L. Zhao and J.L. Zao. Effects of different host plants on the development of AM fungi in the rhizospere of Salvia miltiorrhiza. J. Hebei Univ. 29: 533-537, 2009a.

He, X.L., J. Li and C. He. Effects of AM fungi on the chemical components of Salvia miltiorrhiza Bge. Chin. Agric. Sci. Bull. 25: 182-185, 2009b.

He, X.L., T. Liu and L.L. Zhao. Effects of inoculating AM fungi on physiological characters an nutritional components of Astragalus membranaceus under different $\mathrm{N}$ application levels. Chin. J. Appl. Ecol. 20: 2118-2122, 2009c.

He, X.L., L.Y. Wang, J. Ma and L.L. Zhao. AM fungal diversity in the rhizosphere of Salvia miltiorrhiza in Anguo city of Hebei province. Biodiv. Sci. 18: 187-194, 2010.

He, X.L., L. Ma, J.J. Meng and P. Wang. Effects of AM fungi on the growth and nutrients of Salvia miltiorrhiza Bge. under different soil water and fertilizer conditions. Acta Ecol. Sin. 32: 57215728, 2012a.

He, X.L., P. Wang, L. Ma and J.J. Meng. Effect of three fungicides on arbuscular mycorrhizal fungal infection and growth of Scutellaria baicalensis Georgi. Huan Jing Ke Xue 33: 987-991, 2012b. 
He, X.L., Y.L. Wang and L.L. Zhao. AM fungal genetic diversity in seven medicinal plant rhizospheres in Anguo city of Hebei province. Chin. J. Eco-Agric. 20: 144-150, 2012c.

Huang, J.H., J.F. Tan, H.K. Jie and R.S. Zeng. Effects of invoculating arbuscular mycorrhizal fungi on Artemisia annua growth and its officinal components. Chin. J. Appl. Ecol. 22: 1443-1449, 2011.

Huang, Y.F., H.H. Li, H.Y. Chen and Y Li. Preliminary study on the mycorrhiza inoculation on the seeding of camptotheca acuminate. Guangdong Forest Sci. Technol. 19: 40-42, 2003.

Huang, W.L., X.J. Fan, Z.Y. Yan, Y.T. Ma and X.L. Meng. Diversity study of arbuscular mycorrhizal fungi of Coptis deltoidea. J. Chin. Med. Mater. 32: 689-693, 2012.

Jeffries, P., S. Gianinazzi, S. Peretto, K. Turnau and J.M. Barea. The contribution of arbuscular mycorrhizal fungi in sustainable maintenance of plant health and soil fertility. Biol. Fertil. Soils 37: 1-16, 2003.

Jiang, P. and M.Y. Wang. Colonization rate and diversity of AM fungi in the rhizosphere of seven medicinal plants in Xiamen. Acta Ecol. Sin. 32: 4043-4051, 2012.

Jiang, P., M.Y. Wang and J.C. Lu. Arbuscular mycorrhizal fungi associated with medicinal plants in Zhangzhou, Fujian. Mycosystema 31: 676-689, 2012.

Jie, W.G., B.Y. Cai, J.P. Ge and X.F. Yan. Identification of arbuscular mycorrhizal fungi of Phellodendren amurense Rupr. Biotechnology 17: 32-35, 2007.

Jurkiewicz, A., P. Ryszka, T. Anielska, P. Waligórski, D. Białońska, K. Góralska, M. TsimilliMichael and K. Turnau. Optimization of culture conditions of Arnica montana L.: effects of mycorrhizal fungi and competing plants. Mycorrhiza 20: 293-306, 2010.

Kapoor, R., V. Chaudhary and A.K. Bhatnagar. Effects of arbuscular mycorrhiza and phosphorus application on artemisinin concentration in Artemisia annua L. Mycorrhiza 17: 581-587, 2007.

Kapoor, R., B. Giri and K.G. Mukerji. Glomus macrocarpum: a potential bioinoculant to improve essential oil quality and concentration in Dill (Anethum graveolens L.) and Carum (Trachyspermum ammi (Linn.) Sprague). World J. Microbiol. Biotechnol. 18: 459-463, 2002 a.

Kapoor, R., B. Giri and K.G. Mukerji. Mycorrhization of coriander (Coriandrum sativum L.) to enhance the concentration and quality of essential oil. J. Sci. Food Agric. 82: 339-342, 2002b.

Karagiannidis, N., T. Thomidisa, D. Lazari D, E.P. Filotheou and C. Karagiannidou. Effect of three Greek arbuscular mycorrhizal fungi in improving the growth, nutrient concentration, and production of essential oils of oregano and mint plants. Sci. Hortic. 129: 329-334, 2011.

Kaushish, S, A. Kumar, A. Aggarwal and V. Parkash. Influence of inoculation with the endomycorrhizal fungi and Trichoderma viride on morphological and physiological growth parameters of Rauwolfia serpentina Benth. ex Kurtz. Indian J. Microbiol. 52: 295-299, 2012.

Khaosaad, T., H. Vierheilig, M. Nell, K. Zitterl-Eglseer and J. Novak. Arbuscular mycorrhiza alter the concentration of essential oils in oregano (Origanum sp., Lamiaceae). Mycorrhiza 16: 443446, 2006.

Larose, G., R. Chênevert, P. Moutoglis, S. Gagné, Y. Piché and H. Vierheilig. Flavonoid levels in roots of Medicago sativa are modulated by the developmental stage of the symbiosis and the root colonizing arbuscular mycorrhizal fungus. J. Plant. Physiol. 159: 1329-1339, 2002.

Li, C.X. Effect of vesicular-arbuscular mycorrhizal fungi on production of ginseng. J. Chin. Med. Mater. 26: 475-476, 2003a.

$\mathrm{Li}$, C.X. Effects of infecting vesicular-arbuscular mycorrhiza on growth and development of Coix Lachryma-jobi L. J. Shanxi Agric. Univ. 23: 351-353, 2003 b.

Liu, S.L. and X.L. He. Effects of AM fungi on growth of Glycyrrhiza inflata Bat under water stress. J. Nuclear Agric. Sci. 23: 692-696, 2009.

Liu, T. and X.L. He. Research on the formation course of arbuscular mycorrhizae from Astragalus membranaceus (Fisch.) Bunge seedlings. J. Hebei Forest. Orchard Res. 23: 311-314, 2008. 
Liu, J.N., L.J. Wu, S.L. Wei, X. Xiao, C.X. Su, P. Jiang, Z.B. Song, T. Wang and Z.L. Yu. Effects of arbuscular mycorrhizal fungi on the growth, nutrient uptake and glycyrrhizin production of licorice (Glycyrrhiza uralensis Fisch). Plant Growth Regul. 52: 29-39, 2007.

Loomis, W.D. and R. Corteau. Essential oil biosynthesis. Rec. Adv. Phytochem. 6: 147-185, 1972.

Lu, Y.Q., Y. Cui and X.L. He. Effects of AM fungi on biomass and nitrogen content of Atractylodes macrocephala under different nitrogen levels. J. Henan Agric. Sci. 4: 94-96, 2008a.

Lu, Y.Q. and X.L. He. Effects of AM fungi on the chemical composition and growth amount of Atractylodes macrocephala koidz seedling on diffetent N levels. J. Hebei Univ. 25: 650-653, 2005.

Lu, Y.Q. and X.L. He. Effects of AM fungi on photosynthetic pigment of Atractylodes macrocephala under different nitrogen levels. Acta Agric. Bor. Occi. Sin. 17: 314-316, 2008.

Lu, Y.Q., X.L. He and L.Z. Li. Effects of AM fungi on leaf protective enzymes of Atractrlodes macrocephala under different nitrogen levels. Hubei Agric. Sci. 47: 659-660, 2008 b.

Lu, Y.Q., D.X. Wang, X.L. Lu, L.M. Li, Y. Li and X.L. He. Effects of AM fungi on physiological character and nutritional component of Atractylodes macrocephala under different $\mathrm{N}$ levels. Acta Bot. Bor. Occi. Sin. 31: 351-356, 2011.

Ma, J., X.L. He, Z.M. Jiang and L.Y. Wang. Influence of soil factors on arbuscular mycorrhizal fungal infection of Salvia miltiorrhiza. Acta Agric. Bor. Occi. Sin. 18: 194-198, 2009.

Meng, J.J. and X.L. He. Effects of AM fungi on growth and nutritional contents of Salvia miltiorrhiza Bge. Under drought stress. J. Agric. Univ. Hebei 34: 51-61, 2011.

Pang, P.L., D.Q. Chen, Y.T. Chen and F.M. Zhou. The research on the sift and germinate of AMF spore of Ophiopogon japonicas. Modern Chin. Med. 10: 13-14, 2008.

Qi, G.H., L.P. Zhang, W.L. Yang, X.R. Lu and C.L. Li. Effects of arbuscular mycorrhizal fungi on growth and disease resistance of replanted Ginkgo (Ginkgo biloba L.) seedlings. J. Hebei Forest. Orchard Res. 17: 58-61, 2002.

Qi, G.H., L.P. Zhang, W.L. Yang and G.Y. Lv. The effects of abruscular mycorrhiza fungi on Ginkgo (Ginkgo biloba L.) in the field. Hebei Fruits 19: 40-42, 2003.

Rakshapal, S., S. Divya, A. Awasthi and A. Kalra. Technology for efficient and successful delivery of vermicompost colonized bioinoculants in Pogostemon cablin (patchouli) Benth. World J. Microbiol. Biotechnol. 28: 3233-333, 2012.

Ren, J.H., R.X. Liu and Y.L. Li. Study on arbuscular mycorrhizae of Panax notoginseng. Microbiology 34: 224-227, 2007.

Ren, J.H., J.F. Zhang, R.X. Liu and Y.Q. Li. Study on arbuscular mycorrhizae in Taxus chinensis var. mairei. Acta Bot. Bor. Occi. Sin. 28: 1468-1473, 2008.

Rojas-Andrade, R., C.M. Cerda-Garcia-Rojas, J.T. Frias-Hernández, L. Den-dooven, V. OlaldePortugal and A.C. Ramos-Valdivia. Changes in the concentration of trigonelline in a semi-arid leguminous plant (Prosopis laevigata) induced by an arbuscular mycorrhizal fungus during the presymbiotic phase. Mycorrhiza 13: 49-52, 2003.

Rosa-Mera, C.J.D., R. Ferrera-Cerrato, A. Alarcón, M.J. Sánchez-Colín and O.D. David. Arbuscular mycorrhizal fungi and potassium bicarbonate enhance the foliar content of the vinblastine alkaloid in Catharanthus roseus. Plant Soil 349: 367-376, 2011.

Shen, X.L., Q.S. Guo, Z.Y. Liu, G.S. Zhu and Y.X. Liu. Infection progress of arbuscular mycorrhizae on tissue-cultured plantlets of Pinellia ternata. Chin. J. Chin. Mater. Med. 36: 93-96, 2011.

Smith, S.E. and D.J. Read. Mycorrhizal Symbiosis, 3rd edn., Academic Press, London, 2008.

Smith, S.E. and D.J. Read. Mycorrhizal Symbiosis. Academic Press Ltd., London, 1997.

Teng, H.R. and X.L. He. Effects of different AM fungi and N levels on the flavonoid content of Bupleuruin scorzonerifolium Willd. J. Shanxi Agric. Sci. 4: 53-54, 2005.

Toussaint, J.P. Investigating physiological changes in the aeria parts of AM plants: what do we know and where should we be heading? Mycorrhiza 17: 349-353, 2007. 
Toussaint, J.P., M. St-Arnaud and C. Charest. Nitrogen transfer and assimilation between the arbuscular mycorrhizal fungus Glomus intraradices Schenck \& Smith and Ri T-DNA roots of Daucus carota L. in an in vitro compartmented system. Can. J. Microbiol. 50: 251-260, 2004.

Toussaint, J.P., F.A. Smith and S.E. Smith. Arbuscular mycorrhizal fungi can induce the production of phytochemicals in sweet basil irrespective of phosphorus nutrition. Mycorrhiza 17: 291297, 2007.

Turnau, K. and K Haselwandter. Arbuscular mycorrhizal fungi, an essential component of soil microflora in ecosystem restoration. In: S. Gianinazzi, H. Schüepp, J.M. Barea, K. Haselwandter (eds.), Mycorrhizal Technology in Agriculture. From Genes to Mycorrhiza Application. Birkhauser Verlag, Switzerland, 2002, pp. 137-149.

Vierheilig, H., R. Bennett, G. Kiddle, M. Kaldorf and J. Ludwig-Müller. Differences in glucosinolate patterns and arbuscular mycorrhizal status of glucosinolate-containing plant species. New Phytol. 146: 343-352, 2000.

Volpin, H., Y. Elkind, Y. Okon and Y. Kapulnik. A vesicular arbuscular mycorrhizal fungus (Glomus intraradices) induces a defense response in alfalfa roots. Plant Physiol. 104: 683-689, 1994.

Wang, C.Z., S.R. Mehendale, T. Calway and C.S. Yuan. Botanical flavonoids on coronary heart disease. Am. J. Chin. Med. 39: 661-771, 2011 a.

Wang, D.X., Y.Q. Lu and X.L. He. Effects of AM fungi on growth and physiological characters of Atractylodes Macrocephala under different P-applied levels. Acta Bot. Bor. Occi. Sin. 30: 136-142, 2010.

Wang, J., Y. Li, C. Ni, H. Zhang, L. Li and Q. Wang. Cognition research and constitutional classification in Chinese medicine. Am. J. Chin. Med. 39: 651-660, $2011 \mathrm{~b}$.

Wang, L.Y. and X.L. He. The resource and spatio-temproal distribution of AM fungi from Salvia miltiorrhiza in Anguo. J. Agric. Univ. Hebei 32: 73-79, 2009.

Wang, Q., X.L. He, T.S. Chen and W.F. Dou. Ecological research of arbuscular mycorrhizal fungi in rhizosphere of Puerraria lobata. J. Hebei Univ. 26: 420-425, 2006.

Wang, Q., H.Q. Li, Y.R. Du, Y. Li and H.W. Li. Isolation and identification of VA mycorrhizal fungi on Radix gentianae. Biotechnology 8: 19-22, 1998.

Wang, S., M. Tang, Z.C. Niu and H.Q. Zhang. Relationship between AM fungi resources of rare medicinal plants and soil factors in Lishan mountain. Acta Bot. Bor. Occi. Sin. 28: 355-361, 2008.

Wang, P., X.L. He., L.L. Zhao, L. Ma and H.J. Guo. Effects of AM fungi on the growth and microelement of Scuteliaria baiealensis Georgi under different $\mathrm{N}$-applied levels. Acta Agric. Bor. Sin. 27(suppl): 259-263, 2012a.

Wang, X., W.G. Jie and B.Y. Cai. Community composition of the AM fungi of Phellodendron amurense in different habitats. Sci. Sil. Sin. 48: 99-106, 2012b.

Wei, G.T. and H.G. Wang. Effects of VA mycorrhizal fungi on growth, nutrient uptake and effective compounds in Chinese medicinal herb Datura stramonium L. Sci. Agric. Sin. 22: 56-61, 1989.

Wei, G.T. and H.G. Wang. Effect of vesicular-arbuscular mycorrhizal fungi on growth, nutrient uptake and synthesis of volatile oil in Schizonepeta tenuifolia Briq. Chin. J. Chin. Mater. Med. 16(3): 139-142, 1991.

Wu, Q.C. and Q.A. Wei. Arbuscular mycorrhizae of Ginkgo biloba and its correlation with soil available phosphorus. J. Yangtze Univ. 5(3): 49-52, 2008.

Wu, Q.S., W. Liu, H.F. Zhai, X.F. Ye and L.J. Zhao. Influences of AM fungi on growth and root antioxidative enzymes of Trifoliate orange seedlings under salt stress. Acta Agric. Univ. Jiangxiensis 32: 759-762, 2010.

Xing, X.K., Y. Li, Y. Wang and M.P. Zhang. Foundation of dual cultural system of ginseng VA mycorrhiza fungi. J. Jilin Agric. Univ. 25: 154-157, 2003.

Xing, X.K., Y. Li and D. Yolande. Ten species of vam fungi in five ginseng fields of Jili province. J. Jilin Agric. Univ. 22: 41-46, 2000. 
Xu, Z., X. Chen, Z. Zhong, L. Chen and Y. Wang. Ganoderma lucidum polysaccharides: immunomodulation and potential anti-tumor activities. Am. J. Chin. Med. 39: 15-27, 2011.

Xutian, S., D. Cao, J. Wozniak, J. Junion and J. Boisvert. Comprehension of the unique characteristics of traditional Chinese medicine. Am. J. Chin. Med. 40: 231-244, 2012.

Yang, G., L.P. Guo, X.H. Guo, M. Chen, M.L. Chen and J. Zhou. Selectivity infection of arbuscular mycorrhizal fungi in medicinal plants. Chin. J. Inf. Tradit. Chin. Med. 19: 53-55, 2012a.

Yang, L., M.L. Chen, A.J. Shao and G. Yang. Discussion on applications and mechanisms of biocontrol microoganisms used of controlling medicinal plant soil-borne diseases. China J. Chin. Mater. Med. 37: 3188-3192, 2012 b.

Yu, Y., T. Yu, Y. Wang and X.F. Yan. Effect of inoculation time on camptothecin content in arbuscular mycorrhizal Camptotheca acuminate seedlings. Chin. J. Plant Ecol. 34: 687-694, 2010.

Yu, Y., T. Tao, Y. Yang and X.F. Yan. Effect of co-cultivation time on camptothecin content in Camptotheca acuminata seedings after inoculation with arbuscular mycorrhizal fungi. Acta Ecol. Sin. 32: 1370-1377, 2012.

Zeng, Y., L.P. Guo, L.Q. Hang, J. Zhou and Y.Z. Sun. AM and its application in TCM cultivation. World Sci. Technol./Modern TCM Mater. Med. 9: 83-87, 2007.

Zhang, J., D.H. Liu, L.P. Guo, H. Jin, G. Yang and J. Zhou. Effects of arbuscular mycorrhizae fungi on biomass and essential oil in rhizome of Atractylodes lancea in different temperatures. Chin. Tradit. Herb. Drugs 42: 372-375, 2011.

Zhang, J., D.H. Liu, L.P. Guo, H. Jin, J. Zhou and G. Yang. Effects of four AM fungi on growth and essential oil composition in rhizome of Atractylodes lancea. World Sci. Technol./Modern TCM Mater. Med. 12: 779-782, 2010.

Zhang, M.C., Y.J. Jing and J. Ma. The changing of microbial ecological types after the improvement of ginseng soil. J. Jilin Agric. Univ. 12: 42-46, 1990.

Zhang, Y., L.Y. Xie, B.Q. Xiong, M. Zeng and D. Yu. Correlation between the growth of arbuscular mycorrhizal fungi in the rhizosphere and the flavonoid content in the root of Ginkgo biloba. Mycosystema 23: 133-138, 2004.

Zhao, J.L., H.Y. Deng and X.L. He. Effects of AM fungi on the quality of trueborn Angelica dahurica from Hebei province. Acta Agric. Bor.-Sin. 24: 299-302, 2009.

Zhao, J.L. and X.L. He. Effects of AM fungi on drought resistance and content of chemical components in Angelica dahurica. Acta Agric. Bor. Occi. Sin. 20: 184-189, 2011.

Zhao, P.J., F. An and M. Tang. Effects of arbuscular mycorrhiza fungi on drought resistance of Forsythia suspense. Acta Bot. Bor. Occi. Sin. 27: 396-399, 2007.

Zhao, X., B.W. Wang and X.F. Yan. Effect of arbuscular mycorrhiza on camptothecin content in Camptotheca acuminate seedlings. Acta Ecol. Sin. 26: 1057-1062, 2006.

Zhao, X. and X.F. Yan. Effects of arbuscular mycorrhizal fungi on the growth and absorption of nitrogen and phosphorus in camptotheca acuminate seedlings. J. Plant Ecol. 30: 947-953, 2006.

Zhao, J.L., Q.X. Cheng, X.Y. Gu and B. Lu. Relationship between AM fungi of new eight medicinal plants and soil factors in Anguo of Hebei. J. Henan Agric. Sci. 41: 87-91, 2012.

Zhou, J.H. and J.H. Fang. Effects of AM fungi on the berberine content in Phellodendron chinense seedings. North. Hortic. 12: 25-27, 2007.

Zhou, N., C.L. Xia, B. Jiang, Z.C. Bai, G.N. Liu and X.K. Ma. Arbuscular mycorrhiza in Paris polyphylla var. yunnanensis. Chin. J. Chin. Med. 34: 1768-1772, 2009.

Zhou, N., L. Zou, G.Z. Wang and B. Jiang. Primary explore to relation of arbuscular mycorrhizae and its secondary metabolite steroidal saponin in Paris polyphylla. Chin. J. Exp. Tradit. Med. Form. 16: 85-88, 2010.

Zhou, N., D.Q. Zhang, Q. Sun, B. Jiang and Z.C. Huang. Effects of fungal elicitors on the secondary metabolite steroidal saponin in Paris polyphylla var. yunnanensis. Acta Pharm. Sin. 47: 12371242, 2012. 
Zhu, Y.X., J. Song and W.J. Xiao. Identification of arbuscular mycorrhizal fungi of Salvia mitiorrhiza Bunge in Shiquan of Zhongjiang. Pharm. Clin. Chin. Mater. Med. 2: 17-20, 2011.

Zubek, S. and J. Błaszkowski. Medicinal plants as hosts of arbuscular mycorrhizal fungi and dark septate endophytes. Phytochem. Rev. 8: 571-580, 2009.

Zubek, S., K. Turnau and J. Błaszkowski. Arbuscular mycorrhiza of endemic and endangered plants from the Tatra Mts. Acta Soc. Bot. Pol. 77: 149-156, 2008.

Zubek, S., K. Turnau, M. Tsimilli-Michael and R.J. Strasser. Response of endangered plant species to inoculation with arbuscular mycorrhizal fungi and soil bacteria. Mycorrhiza 19: 113-123, 2009. 